\title{
Plantas utilizadas no paisagismo no litoral do Nordeste ${ }^{(1)}$
}

\author{
VIVIAN LOGES(2), ANA CECILIA RIBEIRO DE CASTRO ${ }^{(3)}$, SIMONE SANTOS LIRA SILVA(2), \\ ANGÉLICA VIRGÍNIA VALOIS MONTARROYOS(2)
}

\begin{abstract}
RESUMO
O paisagismo em áreas litorâneas nem sempre é uma atividade fácil devido às condições ambientais em que as plantas são cultivadas, associado ao desconhecimento na escolha das espécies adequadas, proporcionando projetos mais interessantes e adaptados à estas condições, facilitando a manutenção e conservação destes. Apesar da grande diversidade de plantas nativas com potencial ornamental, estas ainda são pouco utilizadas no paisagismo em áreas litorâneas do nordeste, sendo observado utilização predominantemente de espécies exóticas. Este fato demonstra que há muito ainda a ser pesquisado a fim de proporcionar maiores conhecimentos técnicos para a indicação de plantas nativas em projetos de paisagismo no litoral do nordeste.
\end{abstract}

\section{INTRODUÇÃO}

O paisagismo em áreas litorâneas nem sempre é uma atividade fácil devido às condições ambientais em que as plantas são cultivadas. O solo, vento, maresia e qualidade da água de irrigação, associado ao desconhecimento na escolha das espécies adequadas e técnicas de manutenção, muitas vezes acarretam o insucesso do projeto paisagístico. No Brasil, principalmente na região Nordeste, o paisagismo em áreas litorâneas tem exigido conhecimentos específicos em relação à escolha das plantas para a sua elaboração e implantação, seja nos jardins, em grandes cidades, casas de praia ou em hotéis e resorts.

\section{Benefícios do uso de plantas em áreas litorâneas}

Além de embelezar e valorizar os jardins, o uso de vegetação em áreas litorâneas desempenha um importante papel na conservação do solo. O sistema radicular e a parte aérea das plantas sejam árvores, arbustos, plantas de pequeno porte, herbáceas ou forrações, sustentam e protegem o solo, minimizam o impacto do vento, da chuva, o deslizamento superficial e reduzem o processo de erosão provocados pelas marés em áreas a beira mar.

A salsa da praia (Ipomea brasiliensis), por exemplo, pode ser uma opção em áreas da beira da praia para minimizar a erosão causada pelas forças das ondas durante as marés (Figura 1). Além destes benefícios, a utilização de plantas em áreas litorâneas proporcionam sombra, servem de barreira natural ao acesso de pedestres, bem como de alimento e abrigo para pequenos animais e o homem.

\section{Plantas para áreas litorâneas}

A escolha das plantas adequadas podem proporcionar projetos mais interessantes e adaptados às condições litorâneas, facilitando a manutenção e conservação destes. Por outro lado, a utilização de plantas não adaptadas pode acarretar que apresentem problemas fisiológicos e fitofisionomia comprometida, como observado em plantas de Agave spp. e Cyca spp. no litoral de Pernambuco (Figura 2). Diante disso, antes de escolher as espécies que irão compor os jardins de praias, faz-se necessário conhecer as características de desenvolvimento e de adaptabilidade às condições edafoclimáticas de cultivo nas áreas litorâneas, como ventos fortes e solo arenoso. Desta maneira, a seleção de plantas apropriadas para uso em áreas litorâneas garantirá os benefícios proporcionados pelo paisagismo.

As espécies nativas, que ocorrem naturalmente nas regiões de litoral e restinga, são as mais indicadas e devem ser preferidas para compor os jardins ou criar zonas de transição com a beira praia. Adotando esta forma de composição, mantem-se as características naturais das áreas litorâneas e reduz-se a interferência na biodiversidade local. Outro aspecto importante é que as plantas nativas das áreas litorâneas por serem mais adaptadas e, consequentemente, necessitam de menor manutenção, água e fertilizantes. Por exemplo, as espécies mais utilizadas na cobertura do solo em jardins litorâneos no nordeste do Brasil são Zoyzia japonica (Grama esmeralda) (Figura 3) e a Stenotaphrum secundatum (Grama Santo Agostinho ou Grama inglesa), espécies exóticas que requerem cuidados com irrigação, controle de invasoras e aplicação de fertilizantes para o bom desenvolvimento.

Apesar da grande diversidade de plantas nativas com potencial ornamental, estas ainda são pouco utilizadas no paisagismo em áreas litorâneas do nordeste, seja por desconhecimento das espécies ou indisponibilidade de mudas. Plantas não domesticadas ou recém introduzidas em cultivo, muitas vezes não dispõem de informações quanto a forma de propagação ou técnicas de cultivo. Este fato tem levado ao uso de plantas exóticas ou inadequadas para áreas litorâneas, local em que seria mais indicado o uso de plantas nativas.

\footnotetext{
(1) Recebido em 10 de maio de 2013 e aceito para publicação em 30 junho de 2013.

(2)Universidade Federal Rural de Pernambuco - UFRPE, Rua Dom Manuel de Medeiros, s/n, Recife-PE, Brazil. vloges@yahoo.com

${ }^{(3)}$ Embrapa Agroindústria Tropical (CNPAT), Rua Dra. Sara Mesquita, 2270, CEP 60511-110, Fortaleza-CE- Brasil
} 

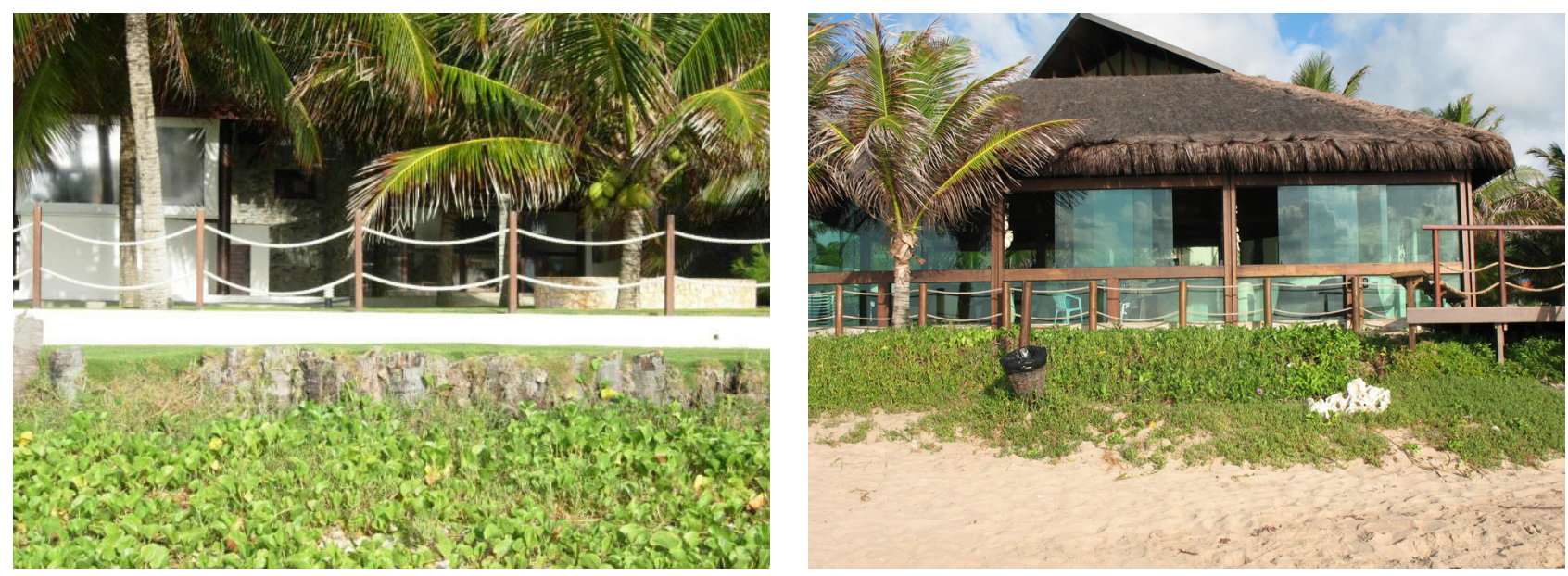

Figura 1. Salsa da praia (Ipomea brasiliensis) em áreas de beira da praia minimizando o efeito das marés.
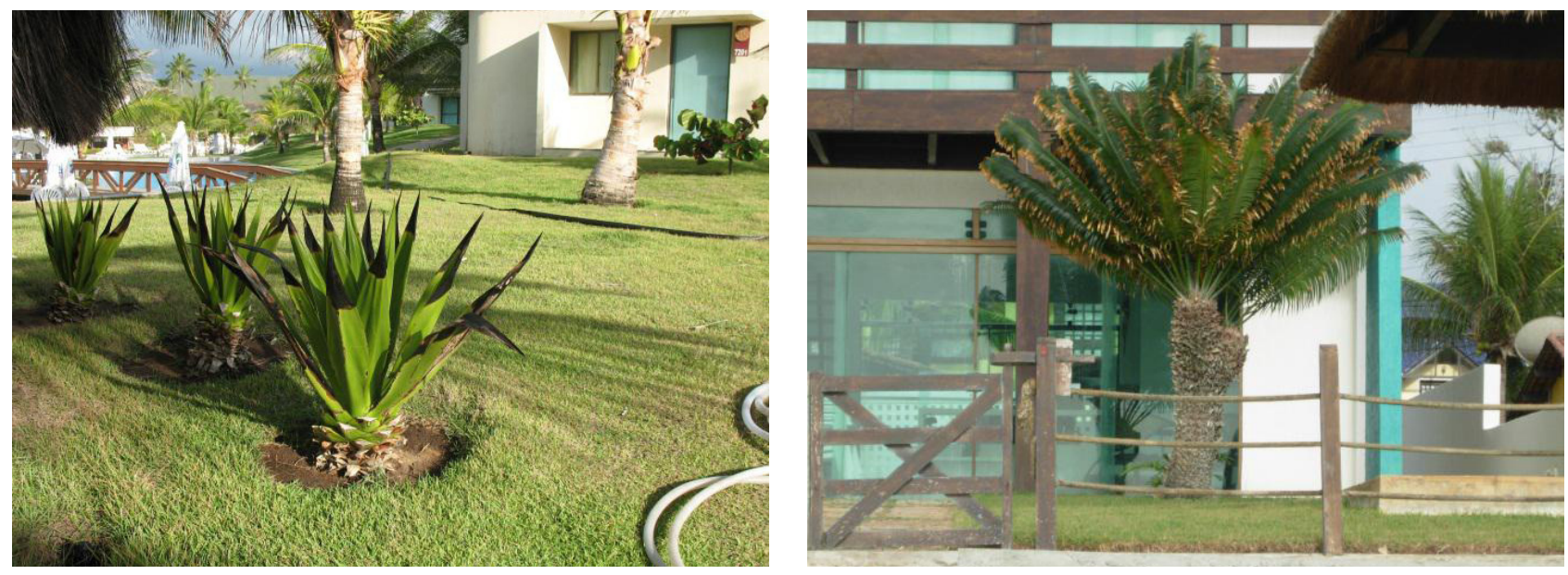

Figura 2. Problemas fisiológicos e fitofisionomia comprometida em Agave spp. e Cyca spp. cultivadas em áreas litorâneas.
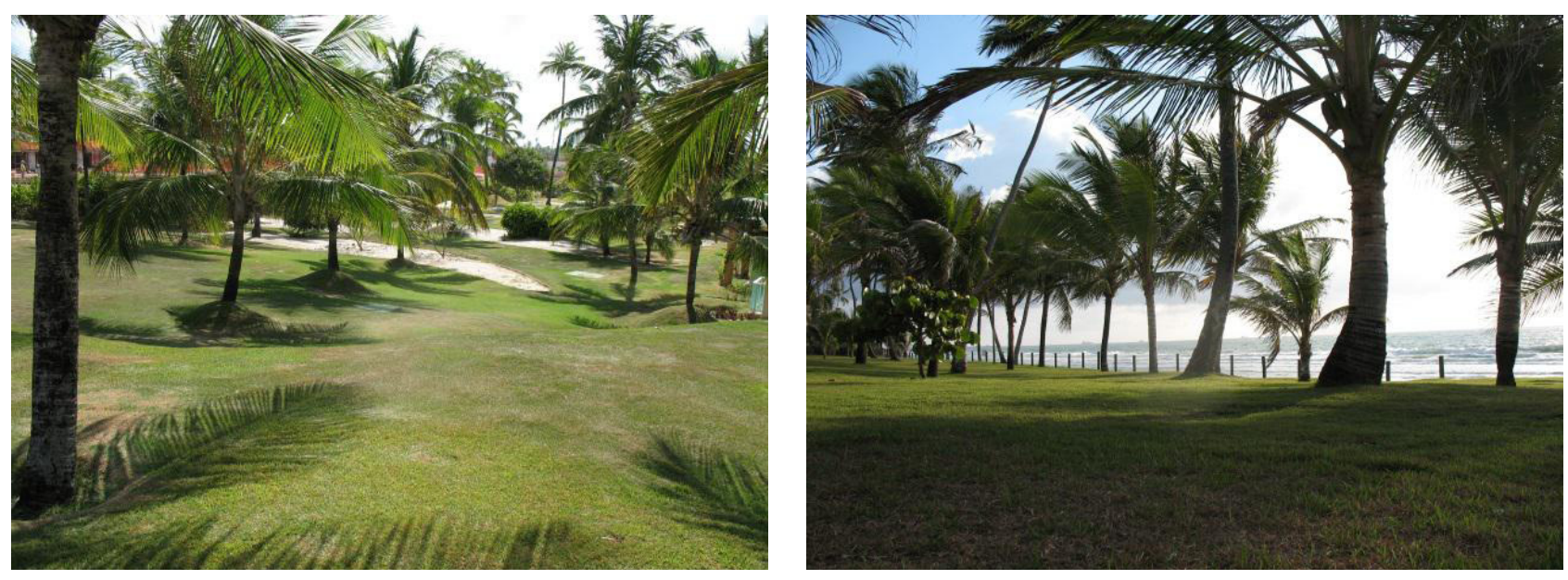

Figura 3. Zoyzia japonica (Grama esmeralda) utilizadas em jardins litorâneas no Nordeste do Brasil.

A introdução de uma espécie exótica pode ser tão bem sucedida, do ponto de vista de adaptação, que pode se transformar num problema ambiental, uma ameaça aos ecossistemas, habitats ou espécies, processo esse conhecido como bioinvasão ou invasão biológica. Espécies exóticas invasoras (animal, vegetal, microrganismos) são reconhecidas, atualmente, como uma das maiores ameaças biológicas ao meio ambiente, com enormes prejuízos à economia, à biodiversidade e aos ecossistemas naturais, sendo consideradas a segunda maior causa de perda de biodiversidade, após as alterações de habitats realizadas pelo homem (MMA, 2013). A Cryptostegia grandiflora (alamanda roxa), por exemplo, é uma espécie originária de Madagascar e foi introduzida como planta ornamental no Brasil. No Ceará se tornou invasora, causando a morte de muitas espécies nativas, em especial as carnaubeiras (Figura 4). Sua disseminação pelo vento (anemocórica) facilitou a dispersão, e por ser resistente aos períodos de 
estiagem, sedimentou sua adaptação.

De acordo com a Convenção sobre Diversidade Biológica, "Espécie Exótica Invasora", é definida como sendo aquela que ameaça ecossistemas, hábitats ou espécies (MMA, 2013) por apresentarem vantagens competitivas em relação à disseminação e adaptação tais como: grande rusticidade em relação aos fatores bióticos e abióticos; grande capacidade para obtenção dos recursos necessários para a sua sobrevivência; grande velocidade de germinação e crescimento (precocidade); grande produção e longevidade dos dissemínulos; diversas formas de propagação; facilidade de dispersão das sementes; manutenção da viabilidade das sementes mesmo em condições desfavoráveis, além de grande desuniformidade da germinação, dificultando o controle químico (SILVA e SILVA, 2007; LORENZI, 2008).
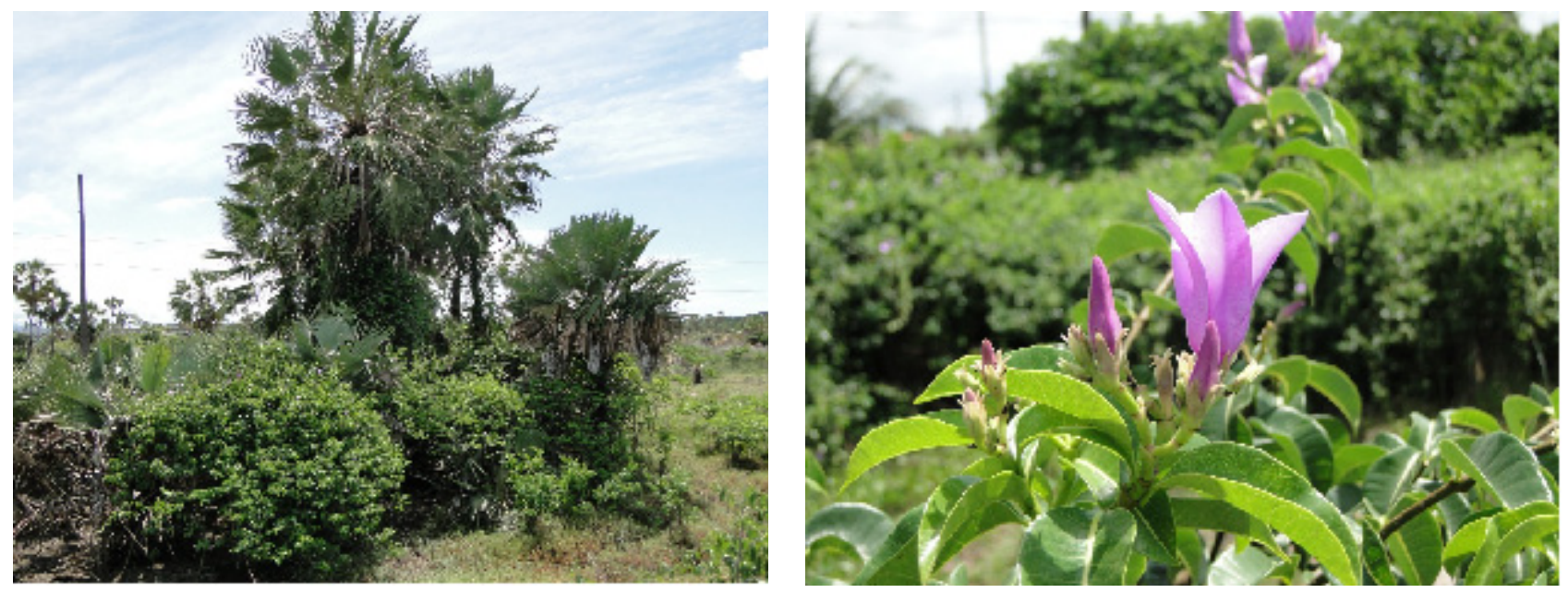

Figura 4. Cryptostegia grandiflora (alamanda roxa) em áreas de ocorrência de carnaubeiras no Ceará.

Inúmeras espécies, algumas nativas e muitas exóticas, vem sendo utilizadas em projetos de paisagismo elaborados por profissionais ou não (habitante paisagista) em áreas litorâneas do nordeste (Tabela 1). O uso de plantas nativas é muito importante do ponto de vista da sustentabilidade ambiental e deveriam ser priorizadas. No entanto, há muito ainda para se pesquisar a fim de proporcionar maiores conhecimentos técnicos para a indicação de espécies nativas em projetos de paisagismo no litoral do nordeste.

Tabela 1. Plantas nativas e exóticas utilizadas em áreas litorâneas do nordeste (identificação baseada em: Lorenzi e Souza, 2008; Lorenzi et al. 1996; Lorenzi, 2008)

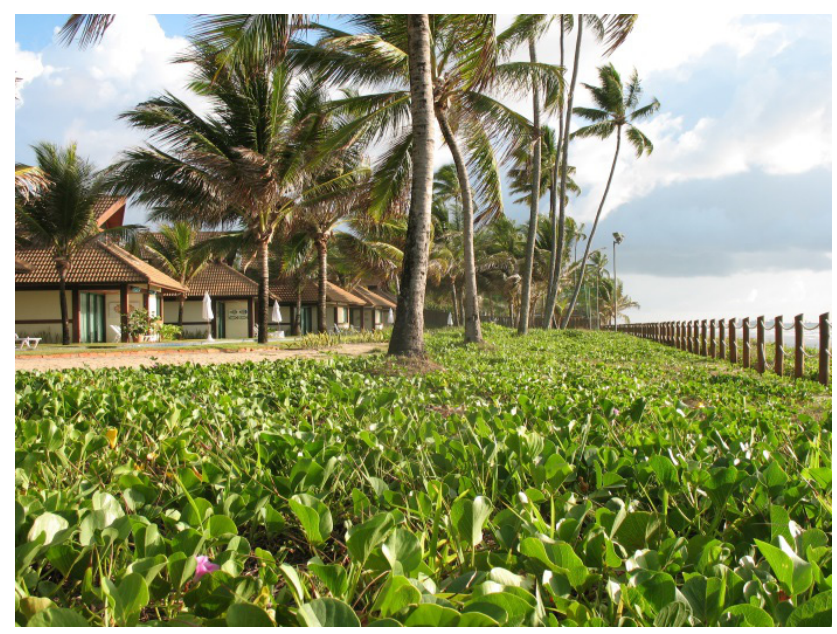

Nome científico: Ipomoea asarifolia, Ipomoea brasiliensis Nome comum: salsa da praia

Forma de uso: Planta nativa, adequada para uso como forrações ou para recobrimento de cercas. É considerada invasora em áreas cultivadas principalmente com cana de açúcar no Nordeste, por apresentar desuniformidade de germinação

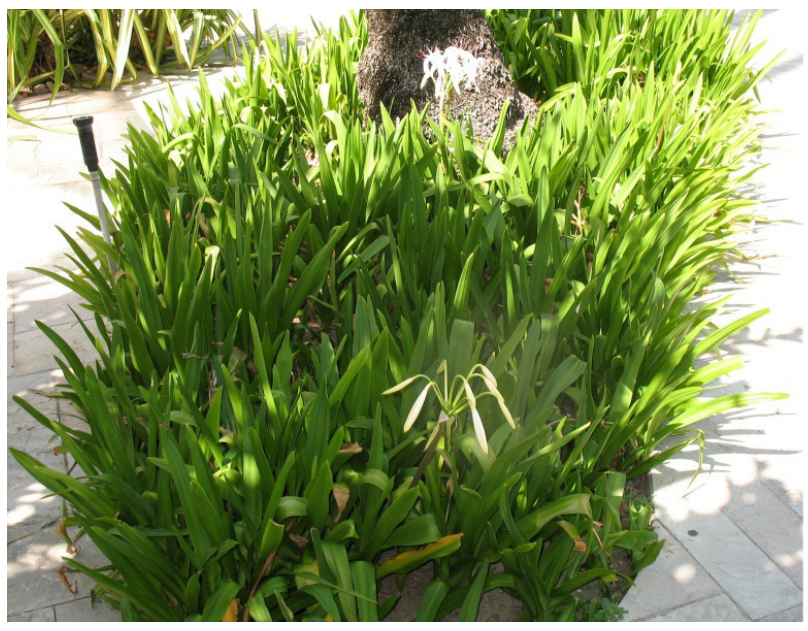

Nome científico: Crinum spp.

Nome comum: Crino branco

Forma de uso: Planta exótica, cultivada em vasos, jardineiras ou diretamente no solo, isoladamente, em canteiros ou formando maciços, a meia sombra ou a pleno sol. 


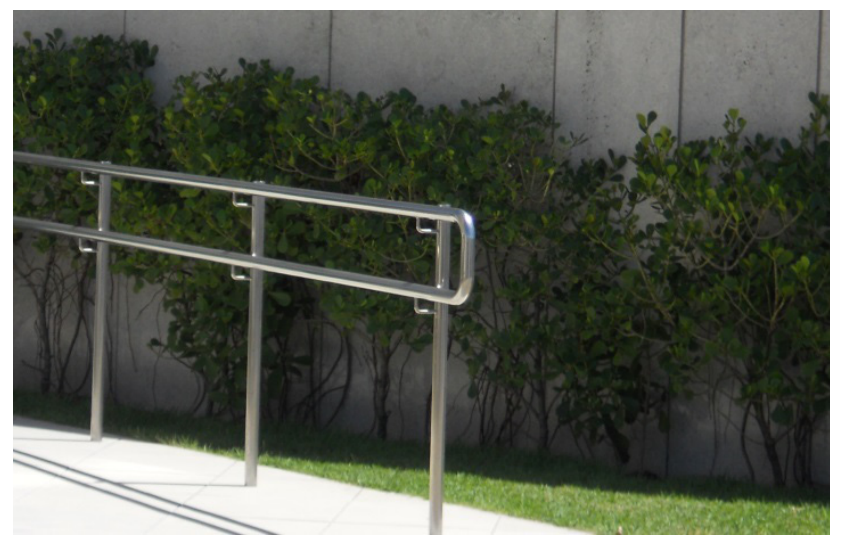

Nome científico: Clusia spp.

Nome comum: Clusia

Forma de uso: Planta nativa, sendo encontrada nas restingas do litoral. Cultivada com frequência em vasos para terraços e interiores, bem como na forma de arbusto isolado ou renque, a pleno sol ou a meia-sombra.

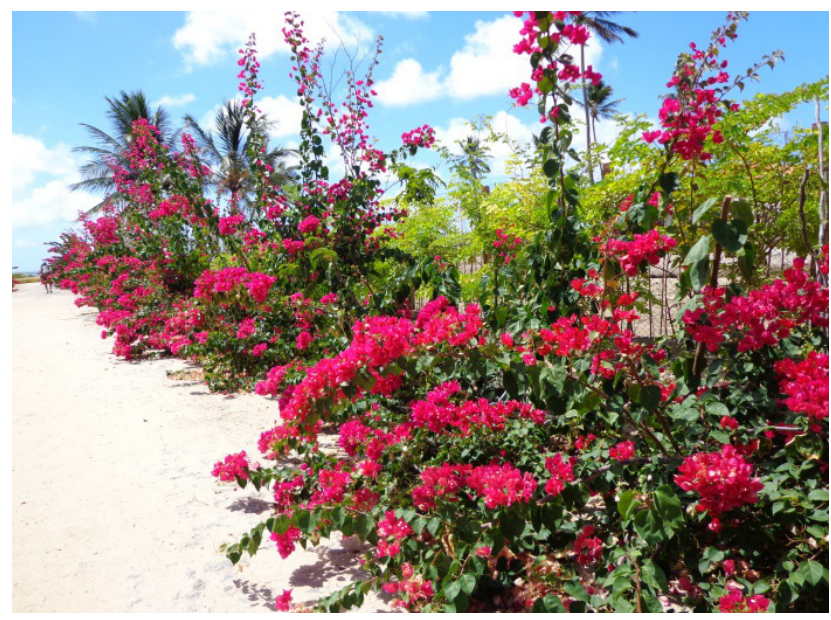

Nome científico: Bougainvillea spectabilis

Nome comum: Buganvile

Forma de uso: Planta exótica, cultivada a pleno sol, como trepadeira para revestir caramanchões e cercas. Flora o ano todo e possui cultivares de inúmeras cores.

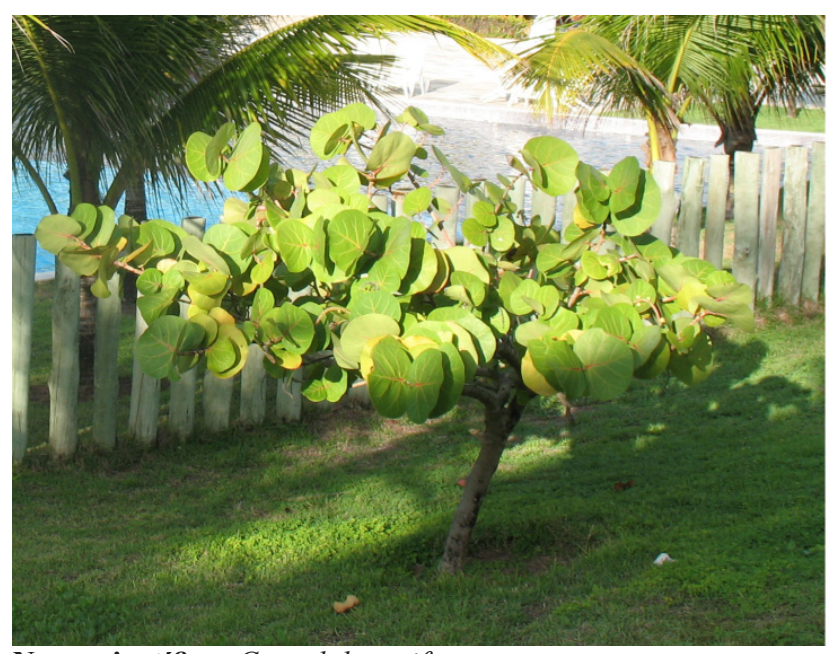

Nome científico: Coccoloba uvifera

Nome comum: Uva da praia

Forma de uso: Planta nativa, de porte arbustivo a arbóreo, pode ser utilizada isolada ou agrupada.

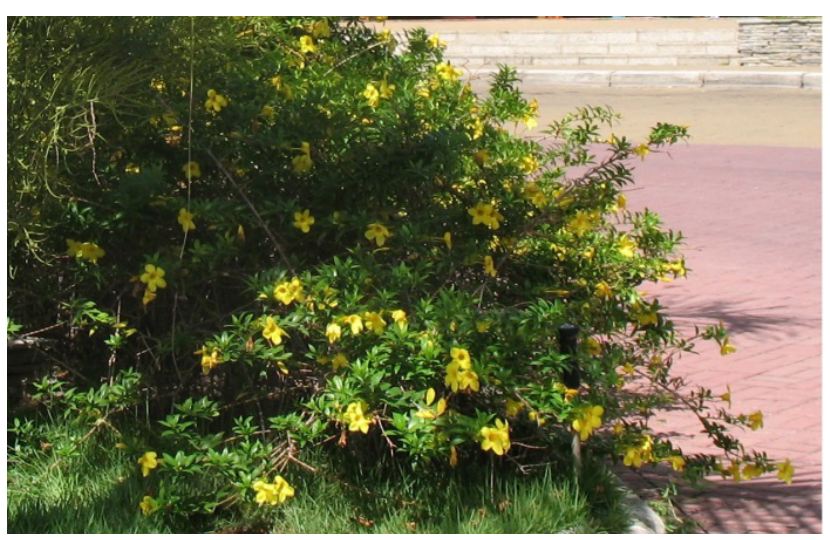

Nome científico: Allamanda cathartica

Nome comum: Alamanda

Forma de uso: Planta nativa, utilizada como trepadeira em cercas ou portais e arbustivas em canteiros a sol pleno.

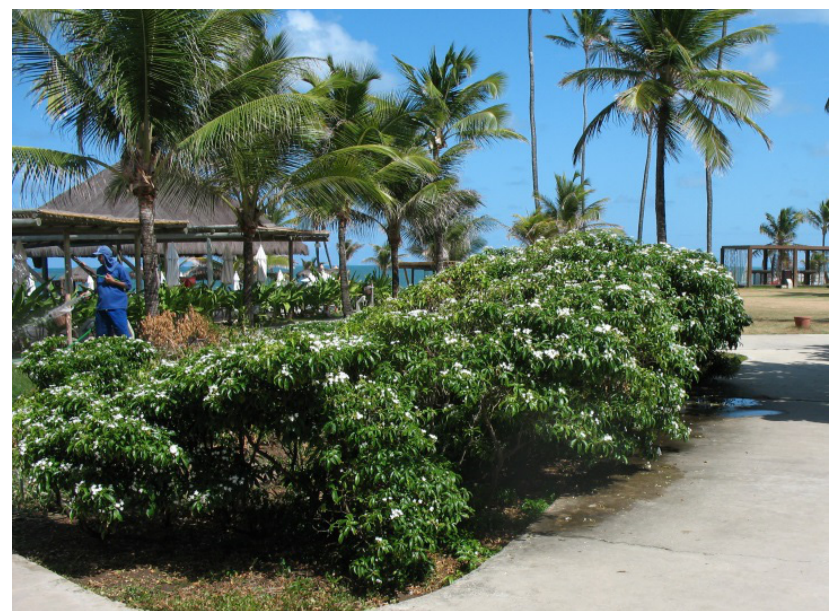

Nome científico: Tabernaemontana laeta

Nome comum: Jasmim de leite

Forma de uso: Planta nativa, de porte arbustivo pode ser utilizada isolada, agrupada ou em renques. Outras espécies do gênero Tabernaemontana são consideras invasoras muito importante por se propagarem rapidamente por sementes e rizomas, os quais são muito profundos e de dificílimo controle.

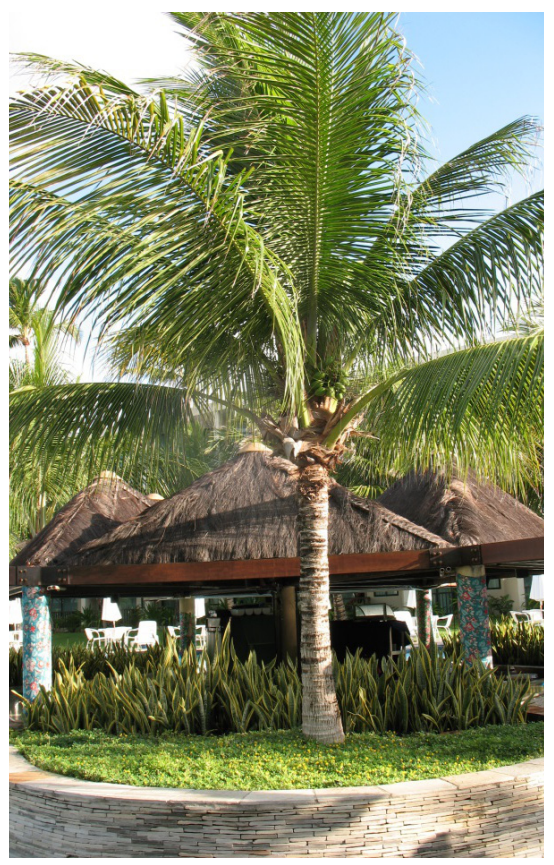

Nome científico:

Cocos nucifera

Nome comum:

Coco, Coco-da-

baía, Coco-da-praia

Forma de uso:

Planta nativa,

característica de

zonas litorâneas

nordestina. 


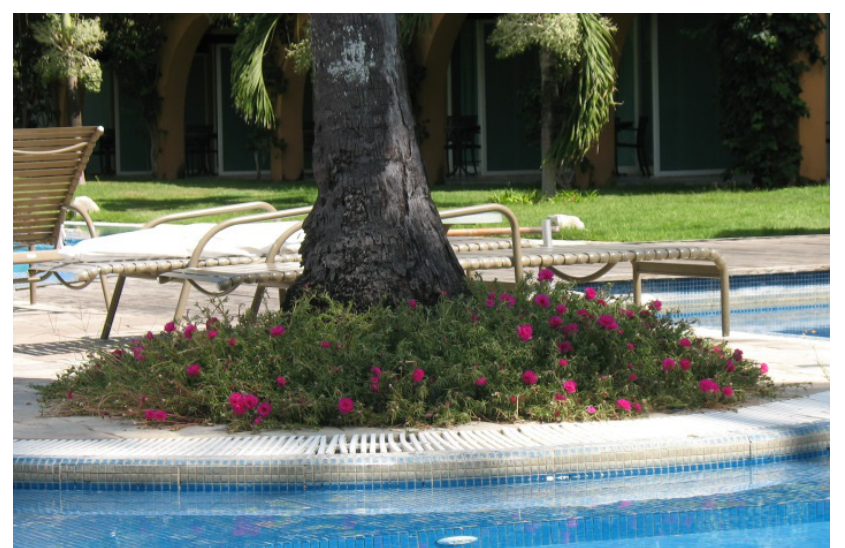

Nome científico: Portulaca spp.

Nome comum: Onze horas

Forma de uso: Planta exótica, utilizada como forração e com cultivares de várias cores que floresce o ano inteiro. Outras espécies do gênero Portulaca são consideradas invasoras em hortas e jardins, apresentando inúmeras sementes por planta com dormência prolongada.

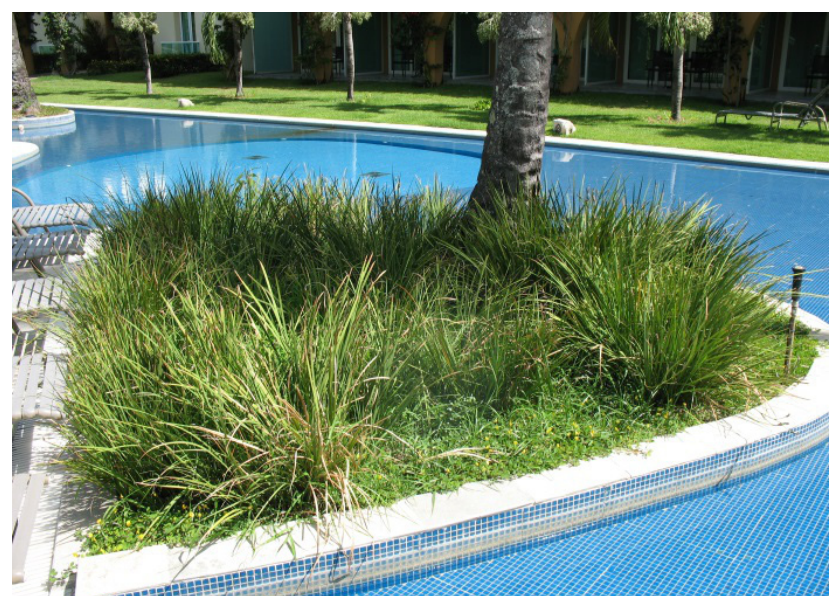

Nome científico: Dietes bicolor

Nome comum: Moréia

Forma de uso: Planta exótica, cultivada em maciços isolados ou em canteiros, vasos e jardineiras.

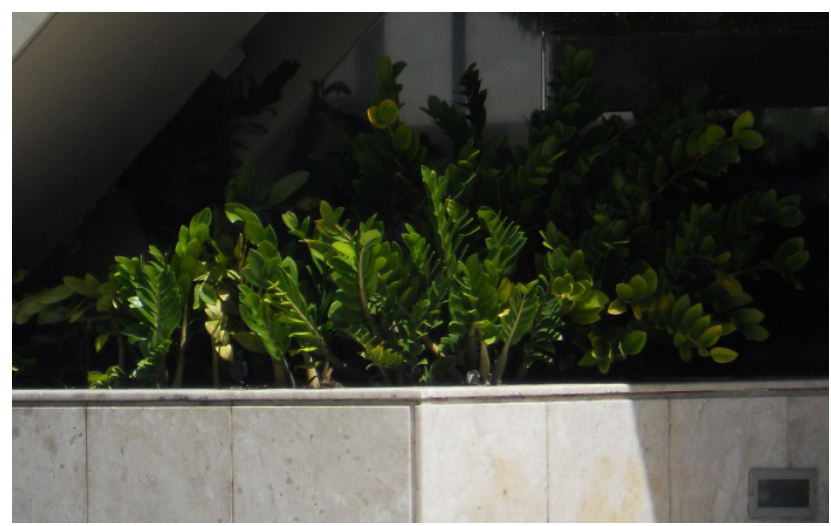

Nome científico: Zamioculcas zamiifolia

Nome comum: Zamia

Forma de uso: Planta exótica, utilizada em vasos ou canteiros em locais sombreados.

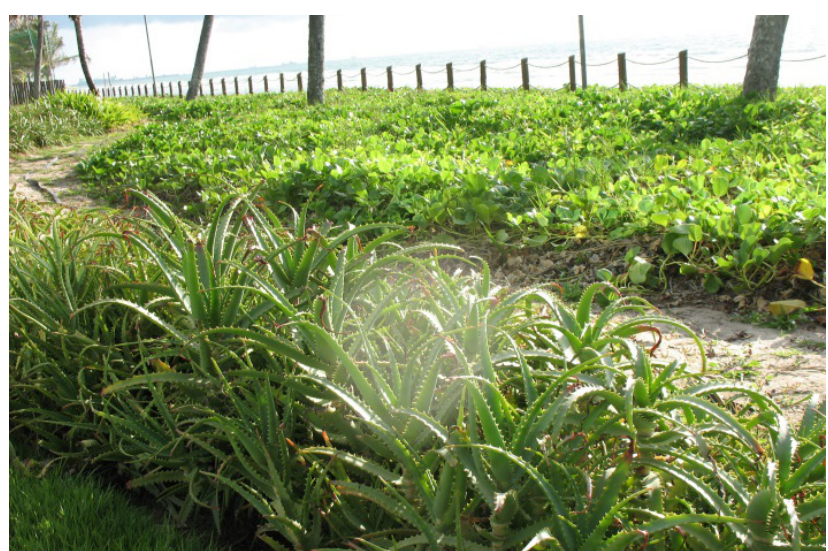

Nome científico: Aloe vera

Nome comum: Babosa

Forma de uso: Planta exótica, que além de medicinal, é muito ornamental, podendo ser usada em jardins de pedra ou cultivada em vasos ou canteiros.

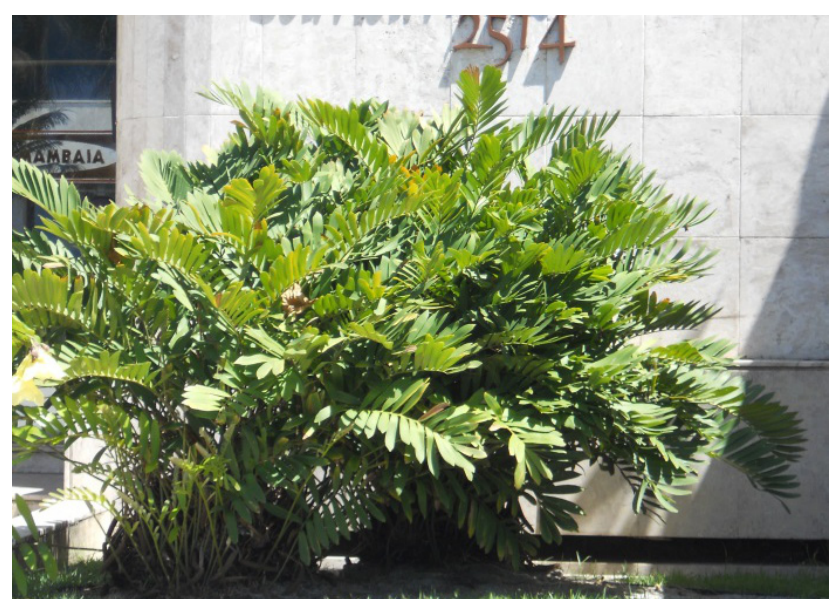

Nome científico: Zamia pumila

Nome comum: Zamia, sagu-da-jamaica

Forma de uso: Planta exótica, pode ser utilizada isolada ou em grupos espaçados, ideal para meia sombra e resiste bem ao vento.

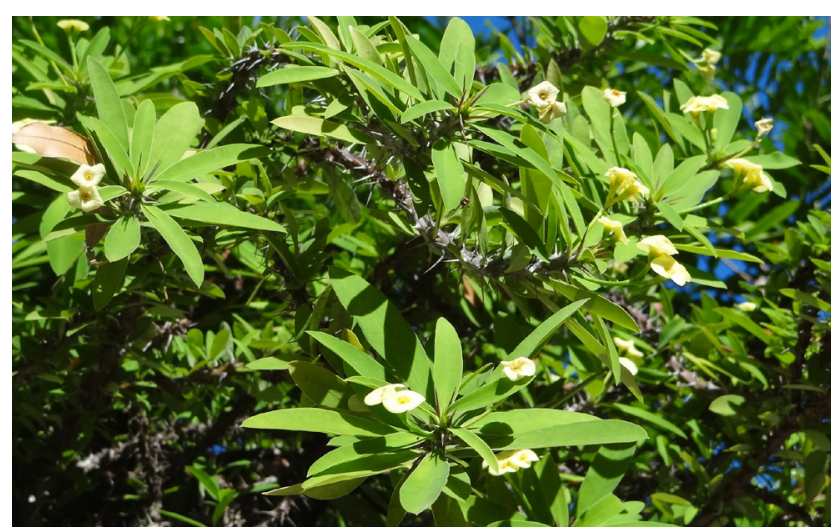

Nome científico: Euphorbia milii

Nome comum: Coroa-de-cristo, coroa-de-espinho

Forma de uso: Planta exótica, adequado para bordaduras ou renques, com função de cerca viva promovendo barreira física. 


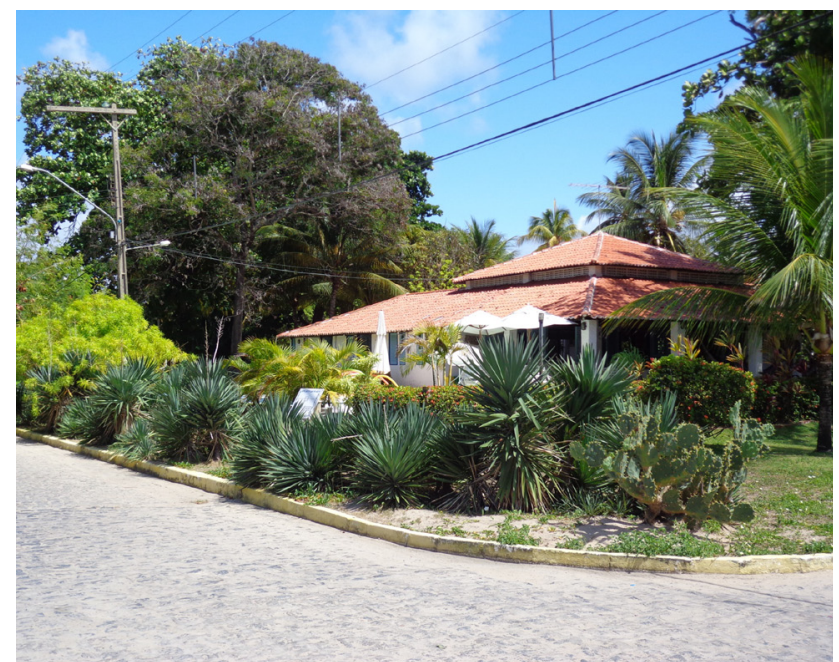

Nome científico: Yucca guatemalensis

Nome comum: Iuca

Forma de uso: Planta exótica, arbustiva semi-lenhosa de aspecto escultural, usada como planta isolada ou agrupada.

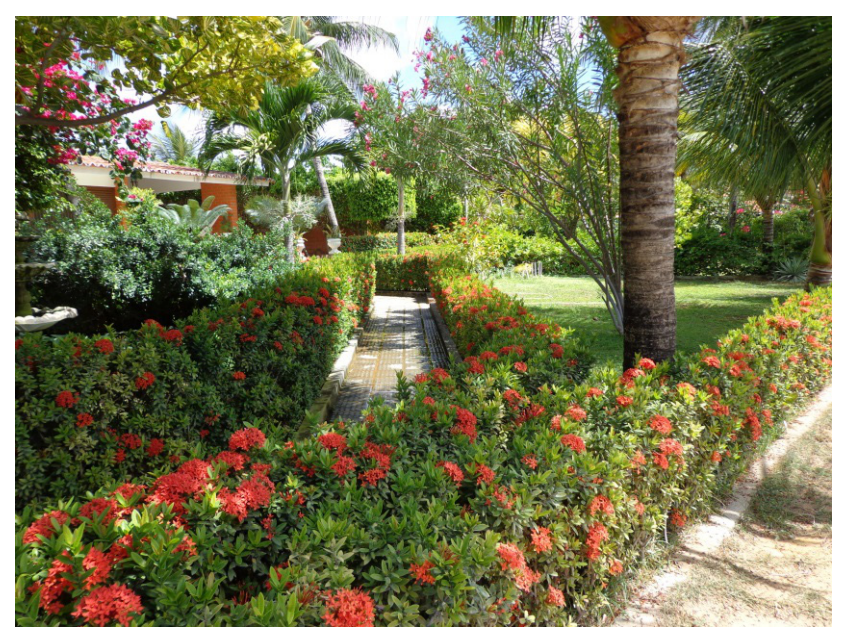

Nome científico: Ixora coccinea

Nome comum: Ixora spp.

Forma de uso: Planta exótica, adequado para bordaduras e renques acompanhando grades, paredes, muros e cercas, em canteiros a pleno sol.

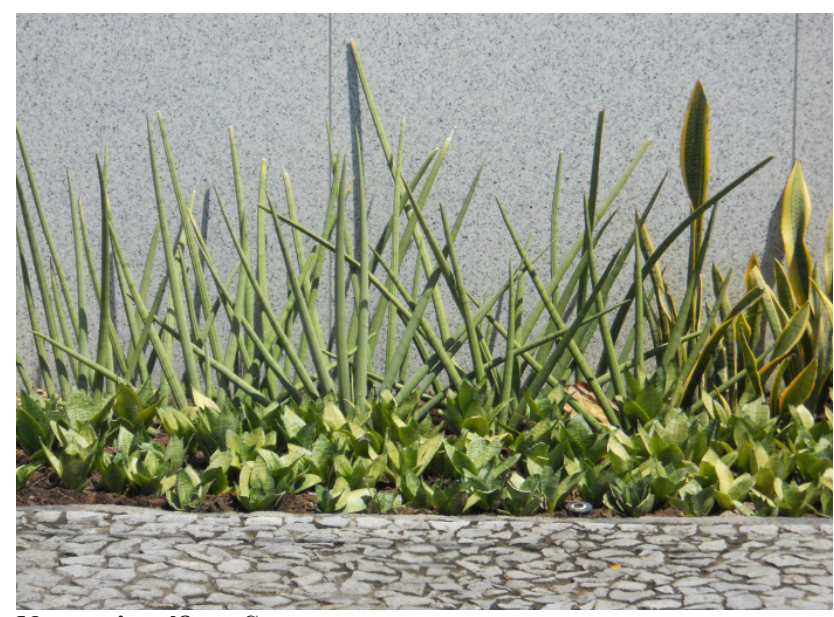

Nome científico: Sansevieria spp.

Nome comum: Espada e lança de são Jorge

Forma de uso: Planta exótica, utilizada em vasos ou canteiros para formar cercas ou maciços.

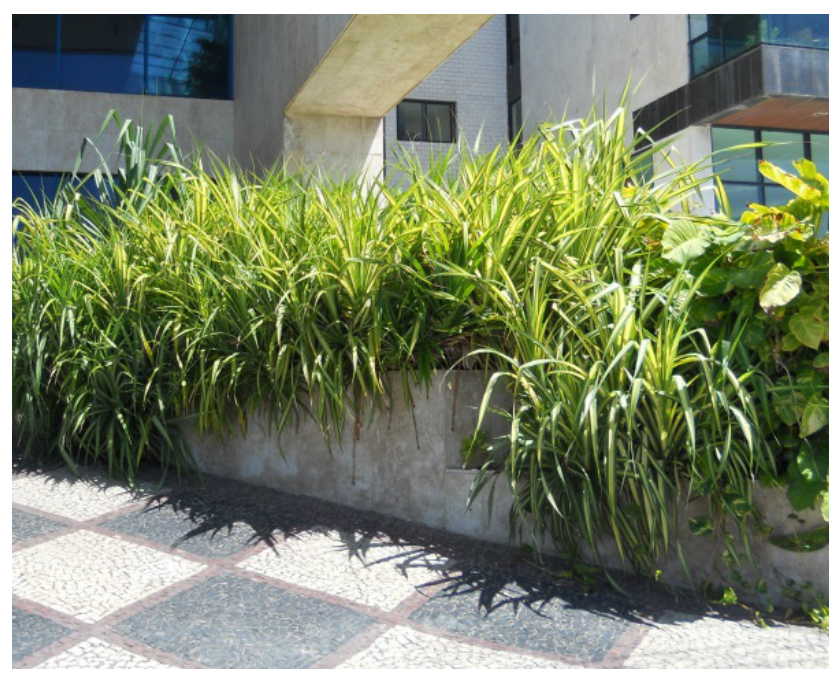

Nome científico: Pandanus spp.

Nome comum: Pândano, pandanus, vacuá

Forma de uso: Planta exótica, de aspecto escultural, pode ser utilizada isolada ou em pequenos grupos como cercas vivas.

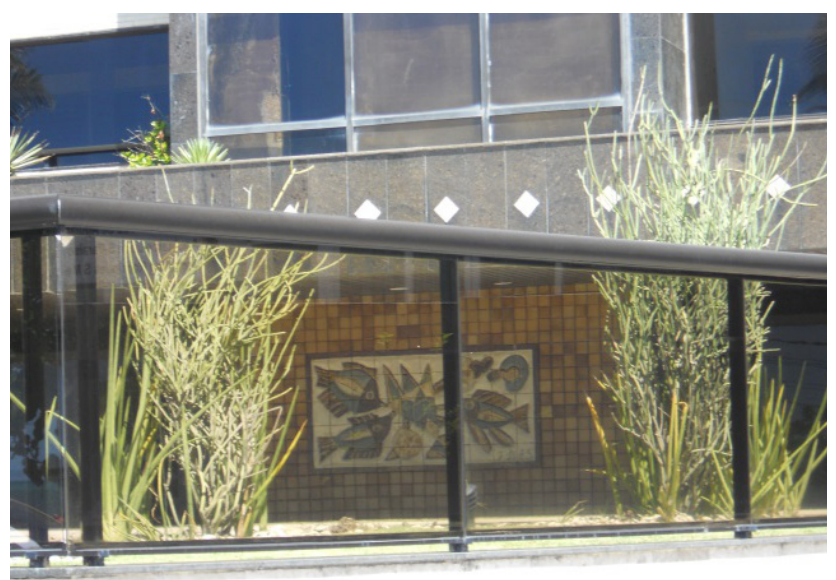

Nome científico: Euphorbia tirucalli

Nome comum: Avelós

Forma de uso: Planta exótica, muito utilizada como cerca viva ou pode ser cultivada isolada.

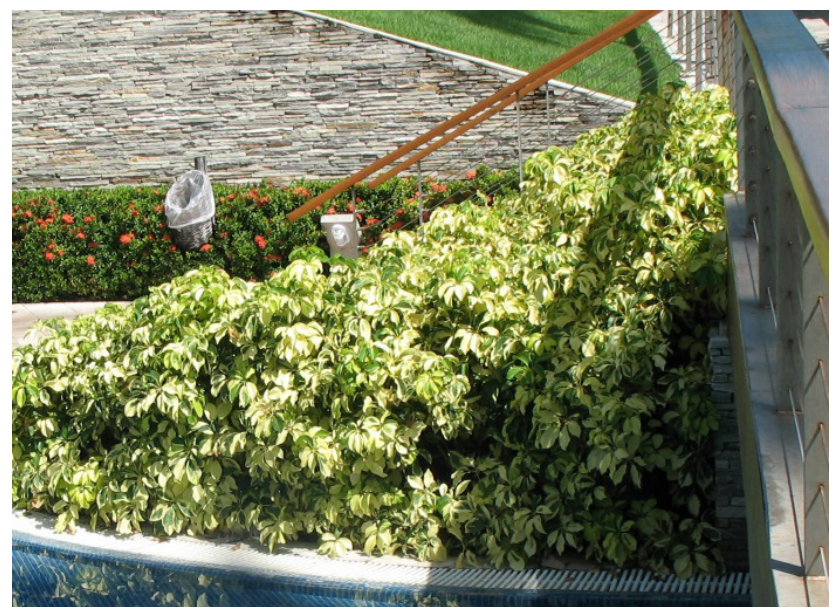

Nome científico: Schefflera spp.

Nome comum: Cheflera, Cheflera-pequena

Forma de uso: Planta exótica de porte arbustivo, pode ser utilizada isolada, agrupada ou em renques. 


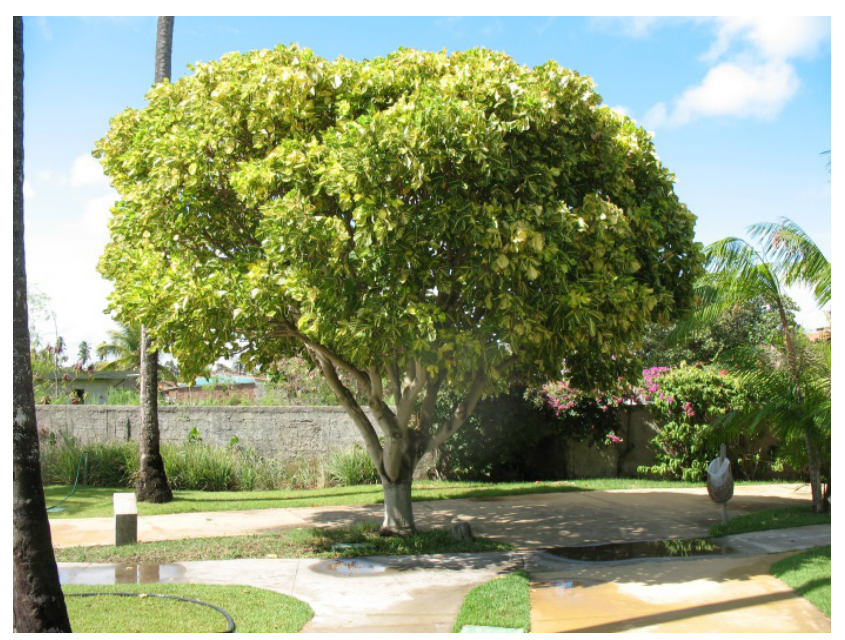

Nome científico: Erythrina variegata

Nome comum: Brasileirinho, Eritrina-verde-amarela

Forma de uso: Planta exótica, de porte arbóreo que se destaca pelo formato e coloração verde amarelas das folhas.

\section{AGRADECIMENTOS}

Aos proprietários dos jardins residenciais e aos resorts, hotéis e pousadas que permitiram a realização das fotos.

\section{REFERÊNCIAS}

Lorenzi, H.; Souza, H.M. de; Medeiros-Costa, J.T. de; Cerqueira, L.S.C. de; Behr, N. von. Palmeiras do Brasil: Nativas e exóticas. Ed. Nova Odessa-SP: Instituto Plantarum, 1996.

Lorenzi, H.; Souza, H.M. de. Plantas ornamentais no Brasil: arbustivas, herbáceas e trepadeiras. 4. Ed. Nova Odessa-SP: Instituto Plantarum, 2008.

LORENZI, H. Plantas daninhas do Brasil: terrestres, aquáticas e tóxicas. 4.ed. São Paulo: Instituto Plantarum, 2008. $672 \mathrm{p}$.

MMA. Ministério do Meio Ambiente. Espécies Exóticas Invasoras. Disponível em: http://www.mma.gov.br/ biodiversidade/biosseguranca/especies-exoticas-invasoras. Acesso em: 14 de abr.2013.

SILVA, A.A. da; SILVA, J.F. da (eds.). Tópicos em manejo de plantas daninhas. MG: Ed. UFV, 2007. 367 p. 